\title{
Improvement and development of the tiltmetric monitoring networks of Neapolitan volcanoes
}

\author{
Ciro Ricco ${ }^{1}$, Ida Aquino ${ }^{1, *}$, Vincenzo Augusti ${ }^{1}$, Luca D’Auria ${ }^{2}$, Carlo Del Gaudio ${ }^{1}$, \\ Giovanni Scarpato ${ }^{1}$ \\ ${ }^{1}$ Istituto Nazionale di Geofisica e Vulcanologia (INGV) - Osservatorio Vesuviano, Napoli, Italy \\ ${ }^{2}$ Instituto Tecnológico y de Energías Renovables (ITER) Tenerife, España
}

\author{
Article history \\ Received July 18, 2017; accepted February 23, 2018. \\ Subject classification: \\ Ground tilt; Volcano monitoring; Borehole sensors; Neapolitan volcanoes; Raspberry Pi 3.
}

\begin{abstract}
The goal of this work is to illustrate the technological development of the tiltmetric monitoring network of Osservatorio Vesuviano, since 1986, retracing the technical steps that led to the current network configuration. This network is devoted to the monitoring of the three Neapolitan volcanoes: Vesuvius, Phlegrean Fields and Ischia Island, which are widely recognized among the volcanic areas with the highest risk worldwide. Ground tilt monitoring had to face numerous technical obstacles, mainly due to background noise characterizing densely urbanized areas like the Neapolitan volcanoes. The network started with the first installations of horizontal optical pendulums that recorded analog signals. In the following years, the network was equipped with electronic sensors more handy and easy to install. A technological leap forward occurred when the first digital sensors were installed in deep boreholes, allowing them to record tilt signals not affected by thermal disturbances. These data are digitally acquired and managed by a datalogger for the data storage and exchange. Currently the network consists of 10 sensors in Phlegrean Fields, 8 in Vesuvius and 3 in Ischia Island, making it one of the densest tiltmetric volcano monitoring network worldwide. This network can boast a database containing thirty years of data acquired by both analog and digital stations. Data consists of both ground tilt and meteorological signals, such as temperature and atmospheric pressure. In these areas they allow a continuous monitoring of the temporal variations of the ground tilt with important implications in understanding the dynamics of these active volcanoes.
\end{abstract}

\section{Introduction}

Ground tilt monitoring is the continuously measurement of changes in the slope of the ground surface. It is able to detect slight tilt variations, in both direction and amplitude, of the volcano edifice caused by the volcano dynamics (e.g. overpressure in a magma chamber, ascent of magma, perturbation of the hydrothermal system). During an inflation episode, the flanks of volcanoes deform reaching variations of inclination of the order of about ten microradians [Dzurusin 2006]. Jointly with other geodetic methods, the study of the angular component of strain allows scientists to better understand the nature of geophysical phenomenon going on in a certain volcanic area [Ricco et al. 2003].

Tilt data, together with tensor strainmeters are used to measure the non-diagonal components $(i \neq j)$ of the deformation tensor (pure tilt in a solid halfspace), while the diagonal components $(i=j)$ of it are filled using data recorded by volumetric strainmeters or dilatometers [Zadro and Braitenberg 1999].

Even the knowledge of the ground tilt alone of fers valuable data for modeling of the strain field. In practice it provides a parameter used to immediately integrate the displacements observed (i.e. by optical levelling, GPS or SAR) on a restless volcanic area [Ricco et al. 2007].

\section{Evolution of ground tilt monitoring instru- ments.}

At the end of 1985, two of authors (C.D.G. and C.R.) set up the first tiltmetric network at Phlegrean Fields. The instrumentation was installed in collaboration with the Institute de Physique du Globe de Paris (I.P.G.P.) [Luongo et al. 1998].

The first station, called DMB, was located in an underground tunnel aligned NS about $15 \mathrm{~m}$ deep, in Pozzuoli Town (Figure 1) and two more stations (DMA and DMC) were installed later. The second station, called BAI, was installed in a gallery below the 


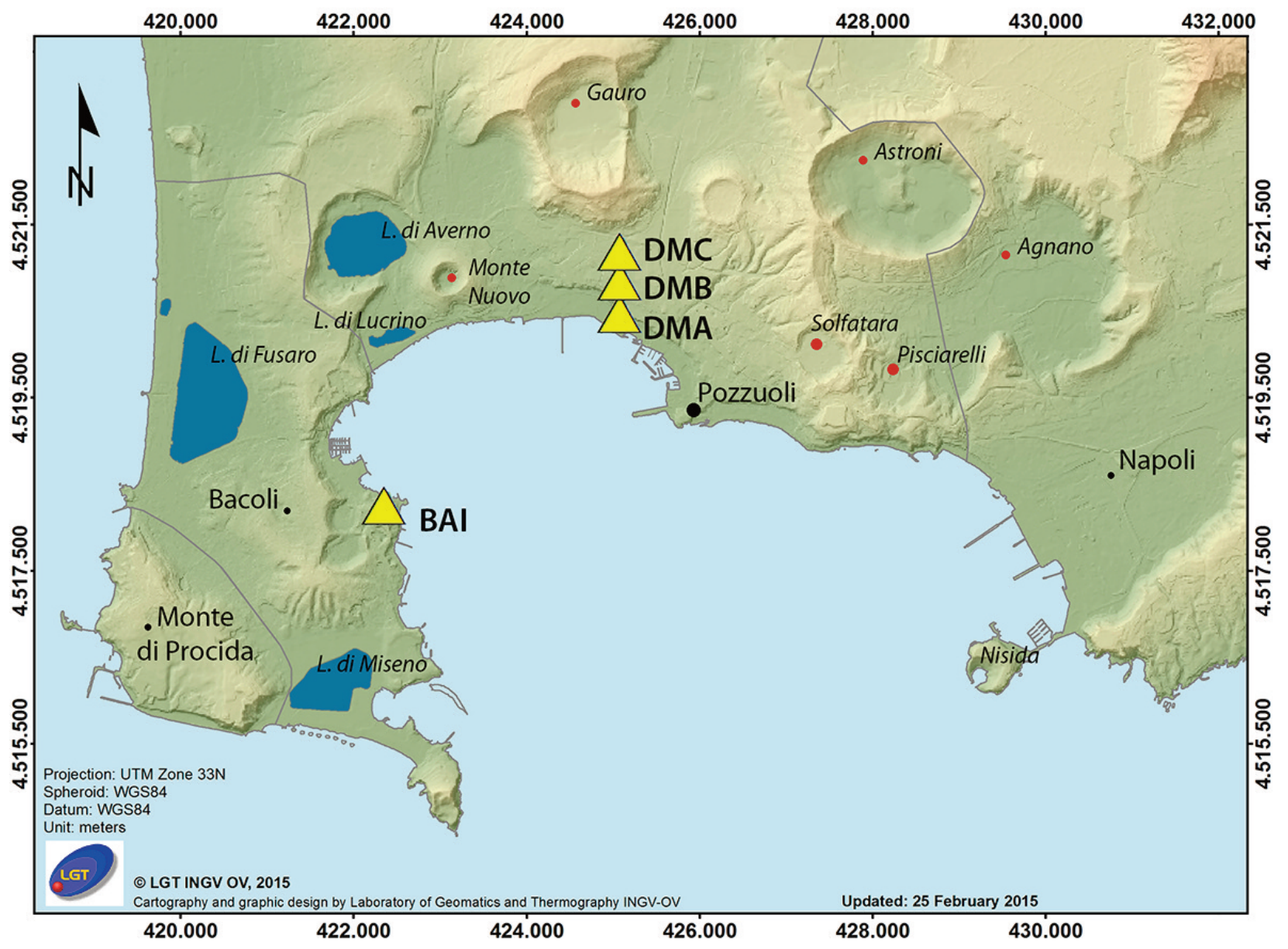

Figure 1. Phlegrean network. First tiltmetric stations equipped with horizontal pendulums and then with electronic sensors.

medieval Baia Castle (Figure 1). Each station was equipped with two horizontal pendulums, sensitive along two orthogonal directions, manufactured by P.A. Blum of I.P.G.P. (Figure 2). Those inclinometers were tightly anchored to the soil through a silica cone fixed in the hole on the base. Their operating principle was based on pendulum rotation that is linearly converted into a variation of electric tension through the coupling between a lamp, mirror and a photocell [Aste et al. 1986, Briole 1987].

Analog signals were digitized through an A/D converter on a Canon X-07 computer (Figure 2). The stations DMB and BAI initially operated with an 8-bit acquisition software allowing data storage in a RAM memory with a sampling rate between 1 and 60 samples-per-hour. Data were recorded in both graphical and numerical form. After about one year, a 12-bit acquisition program was used to control the operation of the whole system (switching the bulb on and off, recording of analog signals, digital conversion and data storage). The stored data were periodically transferred from the datalogger to a computer through a serial interface RS232 directly on the site [Luongo et al. 1998].

These four inclinometers worked for seven years. Subsequently it was decided to replace them with more manageable sensors easier to handle and to install. This despite the higher resolution $\left(10^{-2} \mu\right.$ radians $)$ of horizontal pendulums, which allowed an excellent recording of earth tides. The mobile parts of horizontal pendulums are made in silica (with a coefficient of thermal dilatation $\beta=0.54 \mathrm{ppm} /{ }^{\circ} \mathrm{C}$ ), justifying the superior resolution of these instruments.

Between 1991 and 1992 pendulums were replaced with analog electronic sensors: bi-axial, bubble type, short baselength platform tiltmeters, manufactured by Applied Geomechanics Incorporated (AGI) Model 702 A [AGI 1997] (Figure 3). These instruments are made of steel and contain two transducers (one for each axis) formed by glass cases (containing an electrolytic liquid) closed at the ends by two excitation electrodes. The movement of the bubbles, triggered by ground inclination, changes the electrical resistance between the pick-up and each excitation electrode. Hence, through a bridged electric circuit, it produces a voltage proportional to tilting [AGI 1997]. The signals recorded by each tiltmeter, in addition to temperature recorded by an internal sensor, are A/D converted and recorded automatically in ASCII format at sampling rates between 6 and 60 samples-per-hour [Ricco et al. 2003].

From 2006 to 2011 the Phlegrean network was ex- 


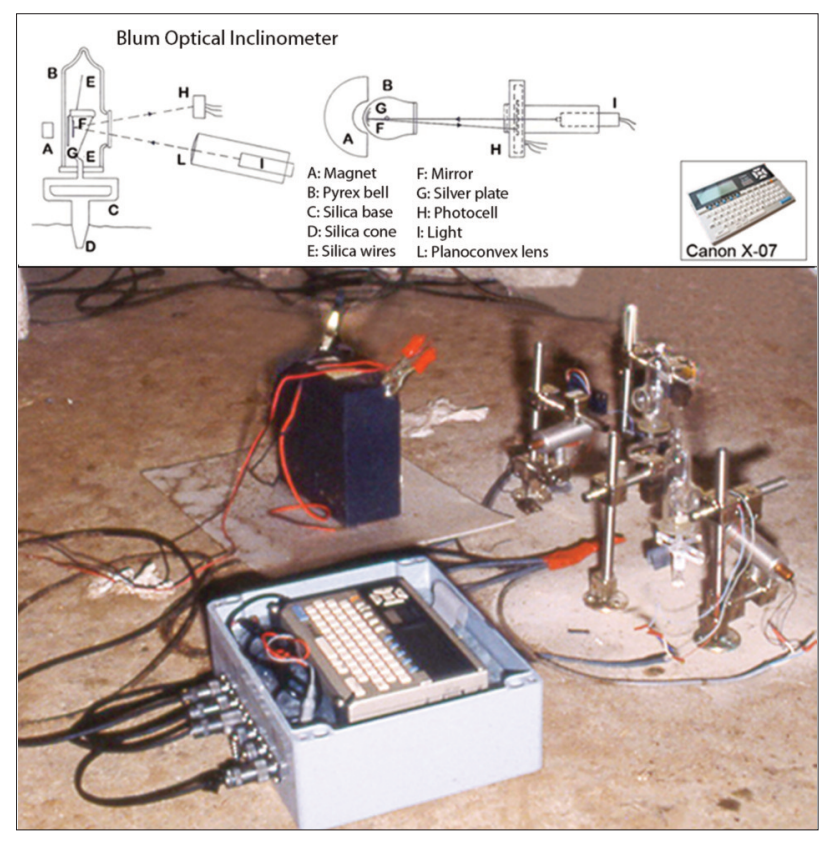

Figure 2. Horizontal pendulums.

tended with CSO, OLB and SLF stations equipped with analog electronic sensors (Figures 3,7).

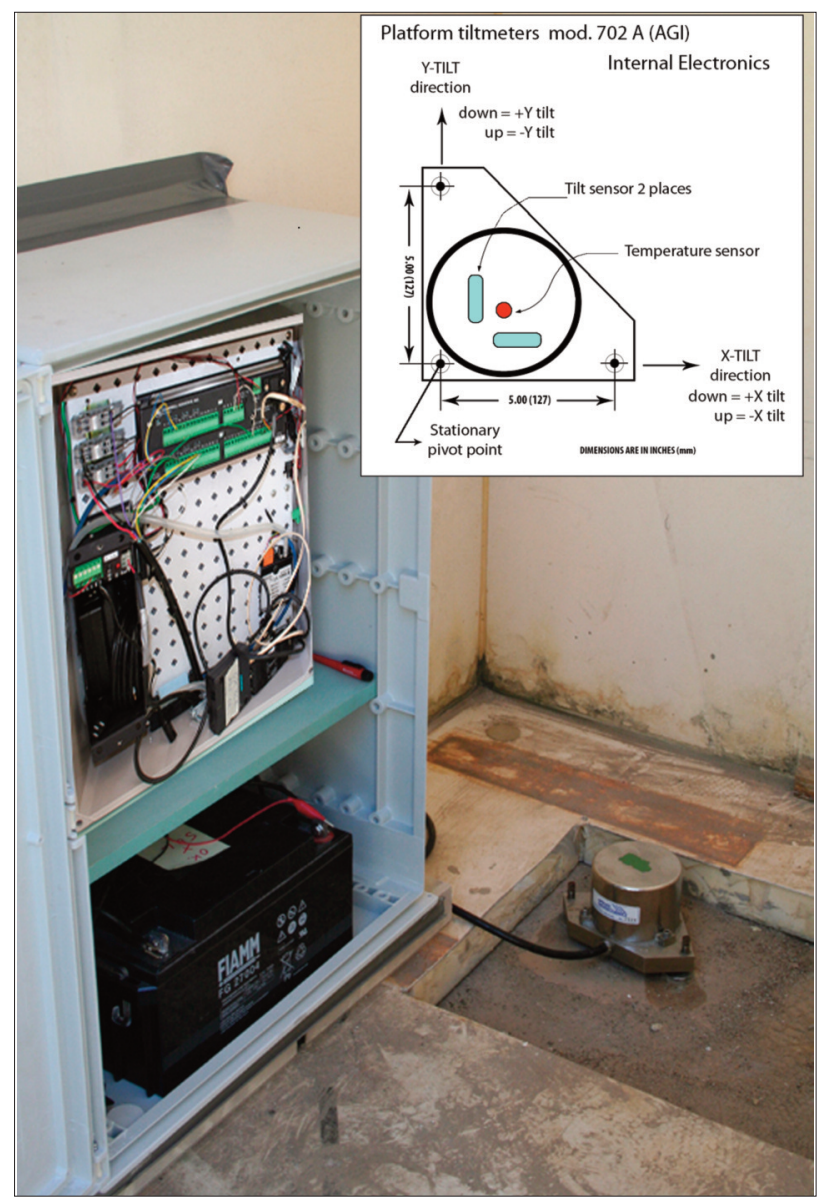

Figure 3. Platform tiltmeter.

On Vesuvius ground tilt monitoring started in 1993, with the installation of the first data acquisition system named OVO. This station was deployed in the gallery of the Osservatorio Vesuviano near the historical building in Ercolano. Afterwards, in 1996, two other stations (CMD and TRC) located at Torre del Greco and Trecase were installed. Each station was equipped with the same sensors of those operating at Phlegrean Fields [Aquino et al. 2006, Ricco et al. 2013] (Figure 4).

All sensors are connected to an electronic control units containing a power supply system, a datalogger for data storage and a data transmission system. The transmission systems currently used are: direct connection to a computer, analog modem for transmission through telephone lines, GSM modem and Internet connection [AGI 2001].

\section{Temperature correction.}

Signals acquired by tilt sensors can be significantly conditioned by temperature range. Bubble-tiltmeters are very sensitive to daily thermal variations whose source is the solar radiation unevenly heating the ground [AGI 1995]. This effect is proportional to the thermal dilatation of the invar screws mounted at the sensor's base. For this reason, these screws have to be of the same length. Even the electrolytic transducer is subject to thermal fluctuations since the liquid is subjected to contraction and expansion with the consequent change of the scale factor $S F_{\text {cal }}$ (angular coefficient of the calibration line). If we do not take into account these effects due to the difference between the environmental temperature $(\mathrm{Te})$ and the calibration temperature $\left(T_{\mathrm{cal}}\right)$, the measured tilt angle will differ from the actual one. The thermal compensation is calculated through the two correction coefficients $K_{s}$ and $K_{z}$ experimentally determined during calibrations in laboratory.

The coefficients $K_{s}$ and $K_{z}$ of the surface sensors AGI (in high gain) are respectively equal to $\pm 0.0004 /{ }^{\circ} \mathrm{C}$ and 1.5 radians $/{ }^{\circ} \mathrm{C}$. The thermal compensation is hence calculated through the following equation:

$$
\text { Tilt }=S F_{c a l}\left[1+K_{s}\left(T e-T_{c a l}\right)\right] \cdot V-K_{z}\left(T e-T_{c a l}\right)
$$

where $\mathrm{V}$ is the output voltage.

This means that if the temperature variation $\left(\mathrm{Te}-\mathrm{T}_{\text {cal }}\right)$ is $10^{\circ} \mathrm{C}$ and the measured tilt is $10 \mu$ radians the calibration line will change its slope and will not intersect the origin but will show a zero shift of $15 \mu$ radians, even though the error associated to the $K_{s}$ is just $0.04 \mu$ radians.

\section{Borehole tiltmeters}

Tilt signals due to background noise are greatly reduced by installing tiltmeters at depth. In order to reduce the thermal excursions, from 2002 to 2003 , the 


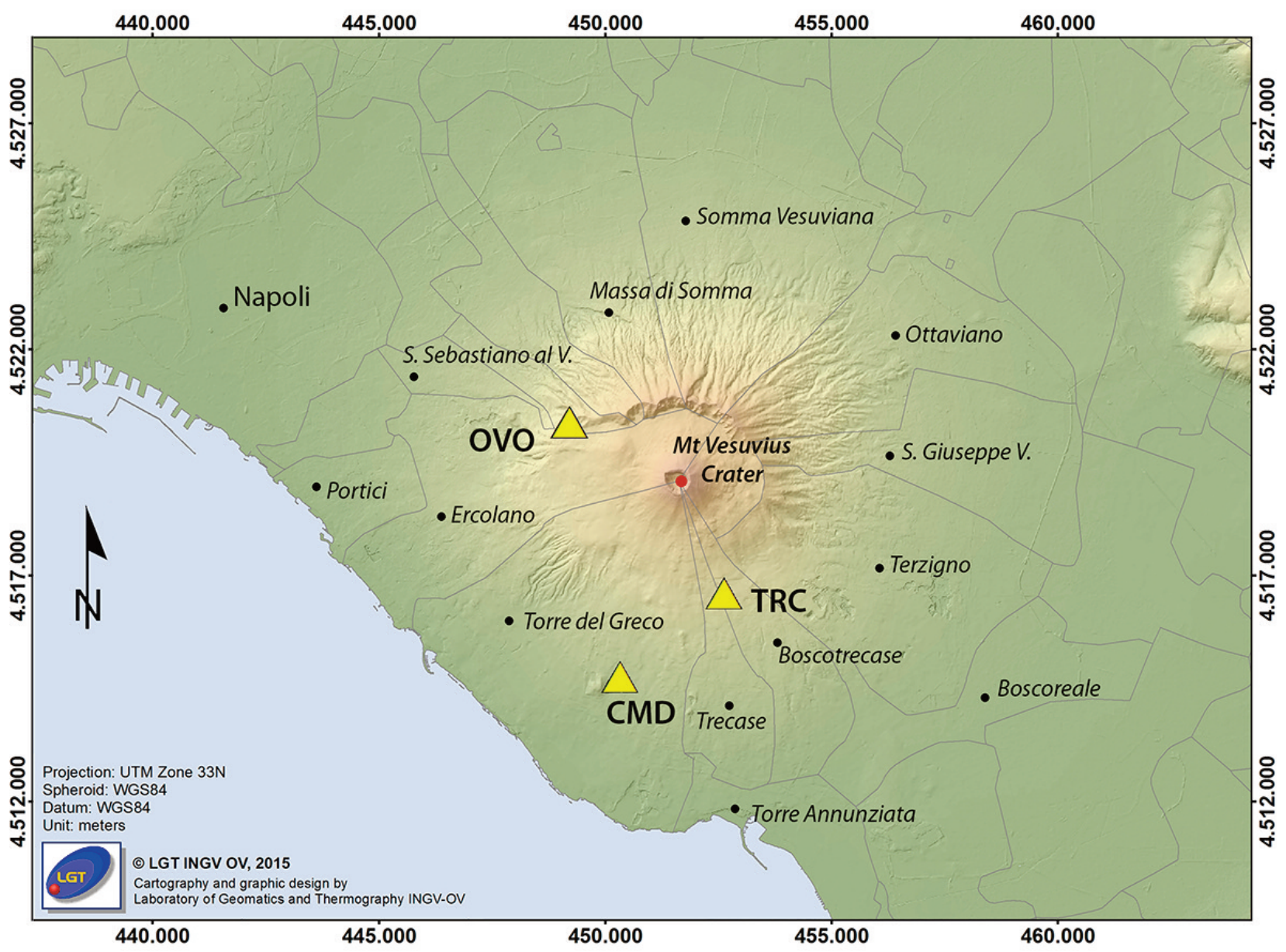

Figure 4. Vesuvius network. First tiltmetric stations equipped with electronic sensors.

Phlegrean Fields tilt network was expanded adding two analog borehole tiltmeters (TOI and ARC) equipped with Model 722 AGI [AGI 1997], installed at $7 \mathrm{~m}$ and $5 \mathrm{~m}$ depth located at Northeast and Southeast of Monte Nuovo (Pozzuoli) (Figures 1,5,7). In 2013 another analog borehole tiltmeter named PSC close to Pisciarelli fumarole field (Figure 1) at $1.5 \mathrm{~m}$ depth was installed (Figures 5,7). The thermal oscillations on their recording are low (Figure 6), although better installations are now realized by positioning borehole tiltmeters at depths greater than $20 \mathrm{~m}$ [Harrison 1976, Harrison and Herbst 1977]. The new electronic sensors (Figure 5) are embedded in stainless steel cylindrical bodies (size $54 \mathrm{x}$ $876 \mathrm{~mm}$ ) to provide the maximum protection, thermal stability, and low-noise performances.

The phenomenon of thermal damping concerns the propagation in the ground of the thermal wave that, on the surface, follows the oscillation of the solar radiation according two main periods: a daily and a yearly period. The attenuation and delay of the thermal wave of period $\mathrm{T}$ as a function of the depth $\mathrm{z}$ and time $\mathrm{t}$ can be expressed as [Tikhonov and Samarskii 2013]:

$$
T_{e}(z, t)=A e^{-\alpha z} \sin (\omega t-\alpha z)
$$

with $\alpha=\sqrt{\frac{\omega}{2 D}}=\sqrt{\frac{\pi}{D T}}$ being the attenuation, $D=\frac{K}{c \rho}$ being the thermal diffusivity and $K, \mathrm{c}, \rho$ respectively the thermal conductivity, specific heat and density.

The thermal wave is therefore a sinusoidal function of time whose amplitude decreases exponentially with depth. The reduction of the amplitude is higher for shorter periods [Tikhonov and Samarskii 2013]. Moreover, it also undergoes a progressive phase shift that can be calculated by $t_{1}-t_{2}=\frac{\alpha z}{\omega}$. For example, for typical rocks $\mathrm{K} \approx 0.0036 \mathrm{~m}^{2} / \mathrm{h}$ while for normal soils $\mathrm{K} \approx 0.0018$ $\mathrm{m}^{2} / \mathrm{h}$. In the former case, at a depth $=25 \mathrm{~m}$, a yearly temperature variation of $25^{\circ} \mathrm{C}$ is reduced to $e^{-\alpha z}=3.7 \times 10^{-4}{ }^{\circ} \mathrm{C}$ and phase shift $t_{1}-t_{2} \approx 1.25$ years, while in the latter $e^{-\alpha z}=1.01 \times 10^{-5}{ }^{\circ} \mathrm{C}$ and $t_{1}-t_{2} \approx 1.8$ years (Figure 6).

\section{Improvement and expansion of tilt network.}

In 2011, the Vesuvius tilt network was expanded by drilling the first four wells on the Vesuvius slopes, at depth ranging from 20 to $28 \mathrm{~m}$ (CCR, IMB, CMT, TRC); four years later, in 2015, another well was drilled (CMG) (Figure 7).

The sensors placed at the bottom of the well record a tilt signal with a lower external temperature disturbance. In the first months of 2015, in the Phlegrean area, three new wells (CMP, ECO, HDM) were 


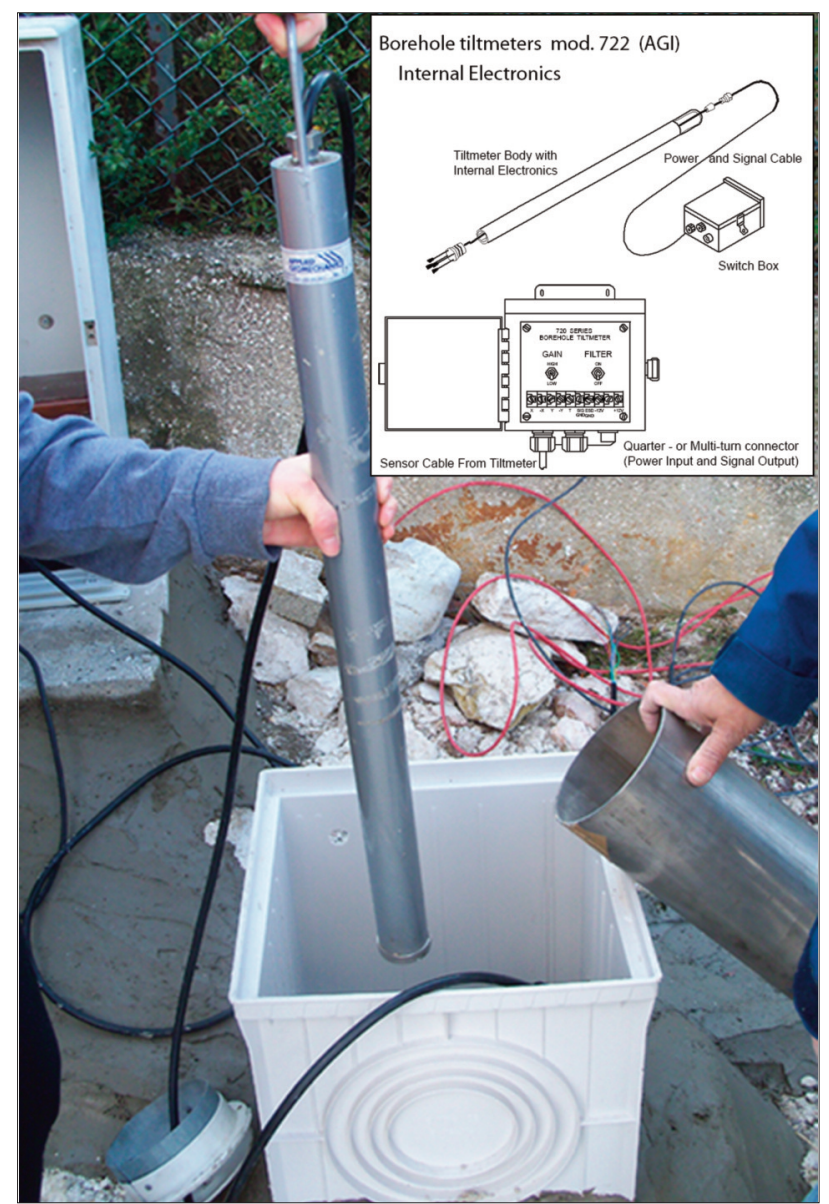

Figure 5. Borehole tiltmeter.

realized at $25 \mathrm{~m}$ depths (Figure 7). This measuring point are located close to the maximum ground uplift area recorded during the last three unrest episodes between 1969-1972, 1982-1984 and 2005-present. Mean- while in 2013 the first site equipped with DMA, DMB and DMC stations (Figure 1) was destroyed due to highway exit construction.

In April 2015, more three wells at $25 \mathrm{~m}$ depths on Ischia Island were drilled (ISC, BRN, FOR), in the surrounding of Mt. Epomeo (Figure 7).

The ten new tiltmetric stations are equipped with digital sensors of the model "Lily Self-Leveling Borehole Tiltmeter" (Jewell Instruments ex AGI) [AGI 2005]; Jewell Instruments, 2013]. They have a cylindrical shape and are made in stainless steel (size $51 \mathrm{x}$ $915 \mathrm{~mm}$ ). At the bottom, bubbles electrolyte, temperature sensor and the magnetic compass (to detect the change of magnetic declination, counter clockwise from $\mathrm{N}$ ), are positioned. The sensing device is a self-levelling sensor on a range of \pm 10 degrees, with a dynamic range of $\pm 330 \mu$ radians and a resolution less than 5 nradians [Aquino et al. 2016] (Figure 8).

The digital electronic converts the tilt signals to data streams, which can be easily transmitted through RS485 / RS422 or RS232 protocols. The streams contain the tilt signals as well as the magnetic azimuth, the temperature, the clock time, the power voltage and the sensor serial number [AGI 2005, Jewell Instruments 2013]. The data are also stored in an internal non-volatile flash memory and subsequently transmitted to the surface, using an interface converter from serial to Ethernet (Lantronics UDS1100 model or similar). Currently the acquisition rate is 1 sample-per-minute and each acquisition is the mean value of 8000 samples.

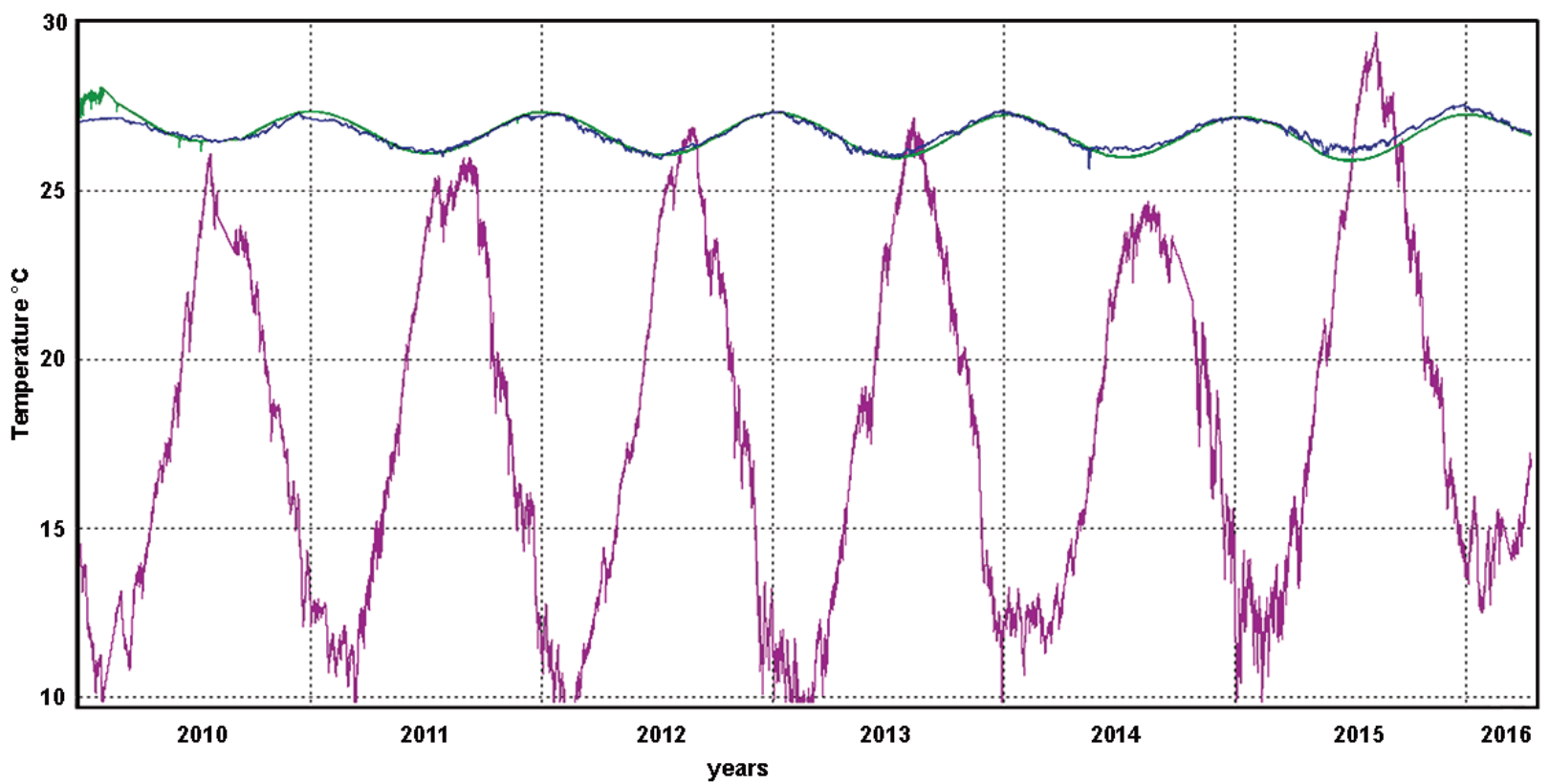

Figure 6. Example of thermal damping at TOI tilt station (equipped with a borehole placed at $7 \mathrm{~m}$ depth). Comparison between temperature recorded at the surface (purple), the same signal attenuated and delayed at the well bottom with $\alpha=0.439$ and $t_{1}-t_{2} \approx 0.5$ years (blue), and temperature recorded at the bottom (green). 
RICCO ET AL.

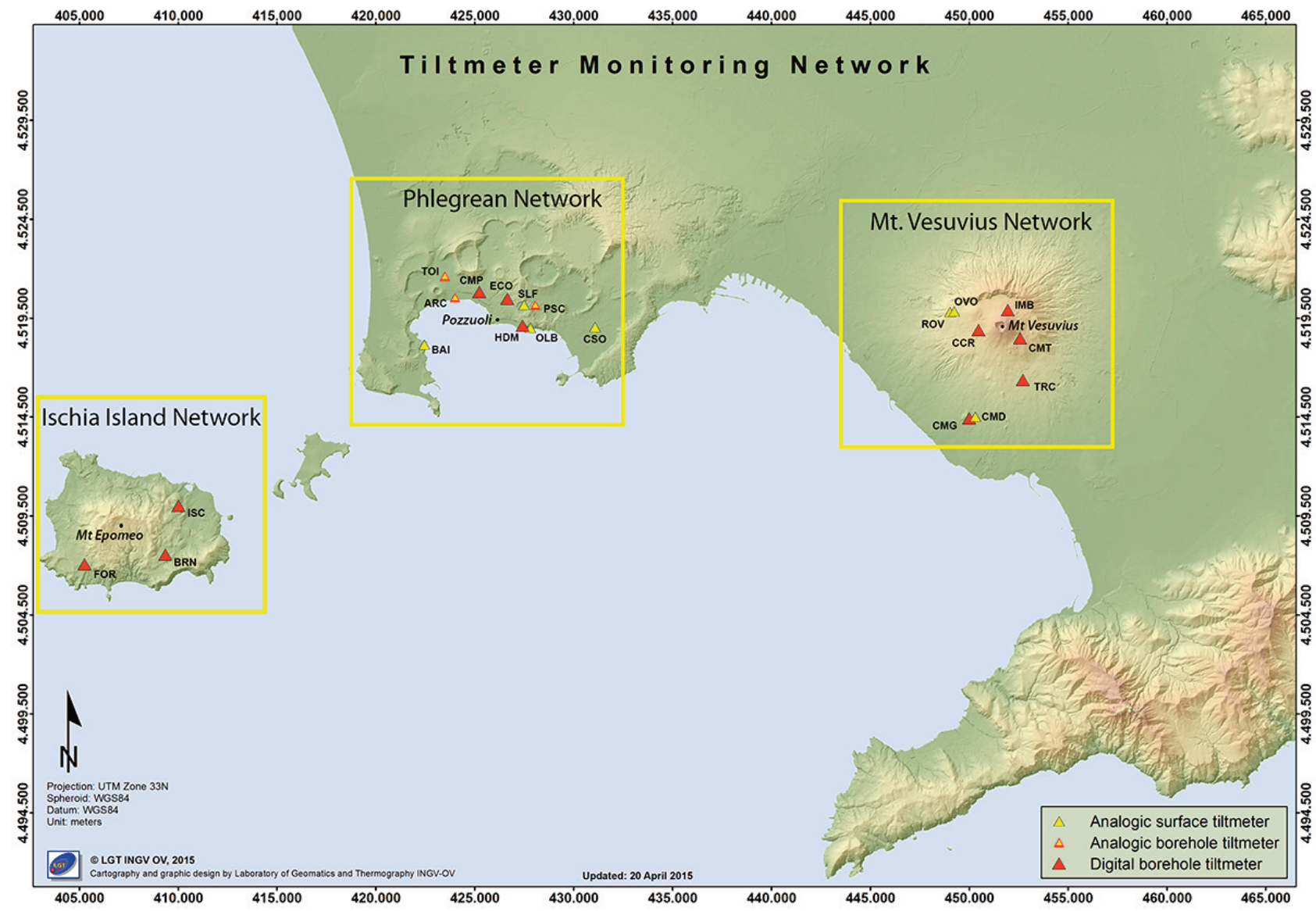

Figure 7. Expansion of tilt network.

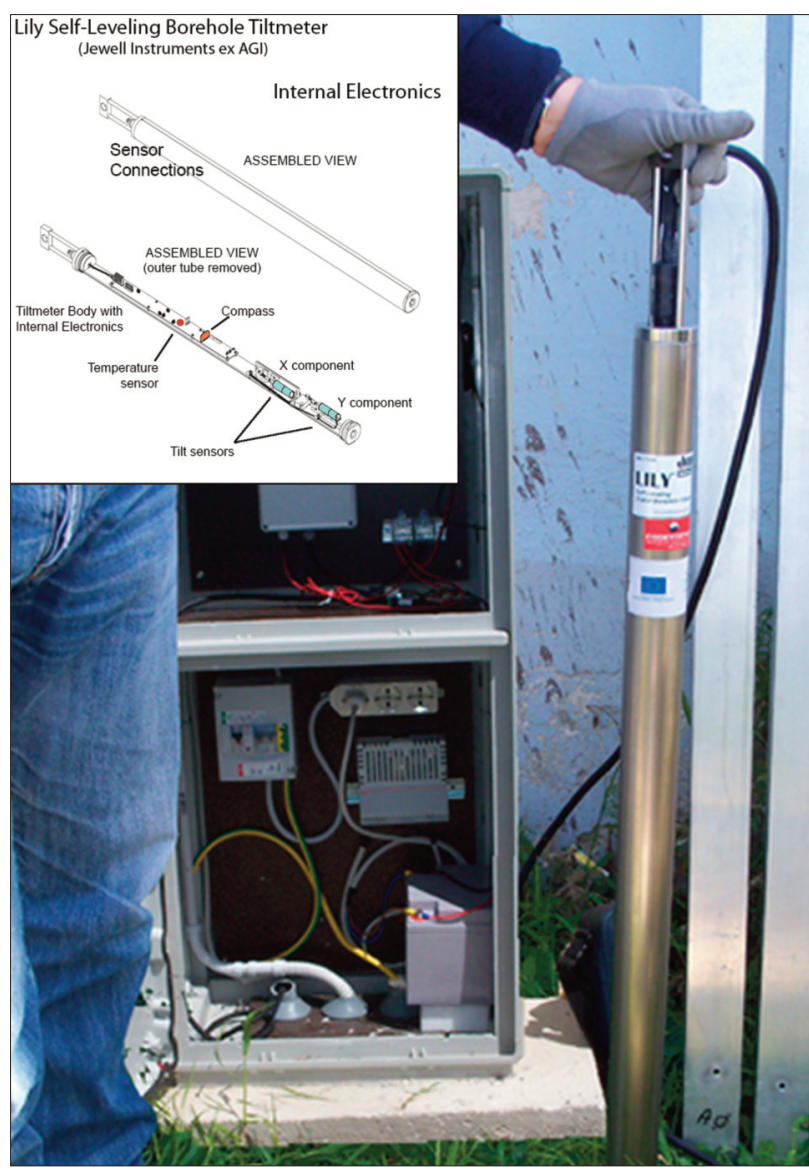

Figure 8. Digital sensor Model Lily.

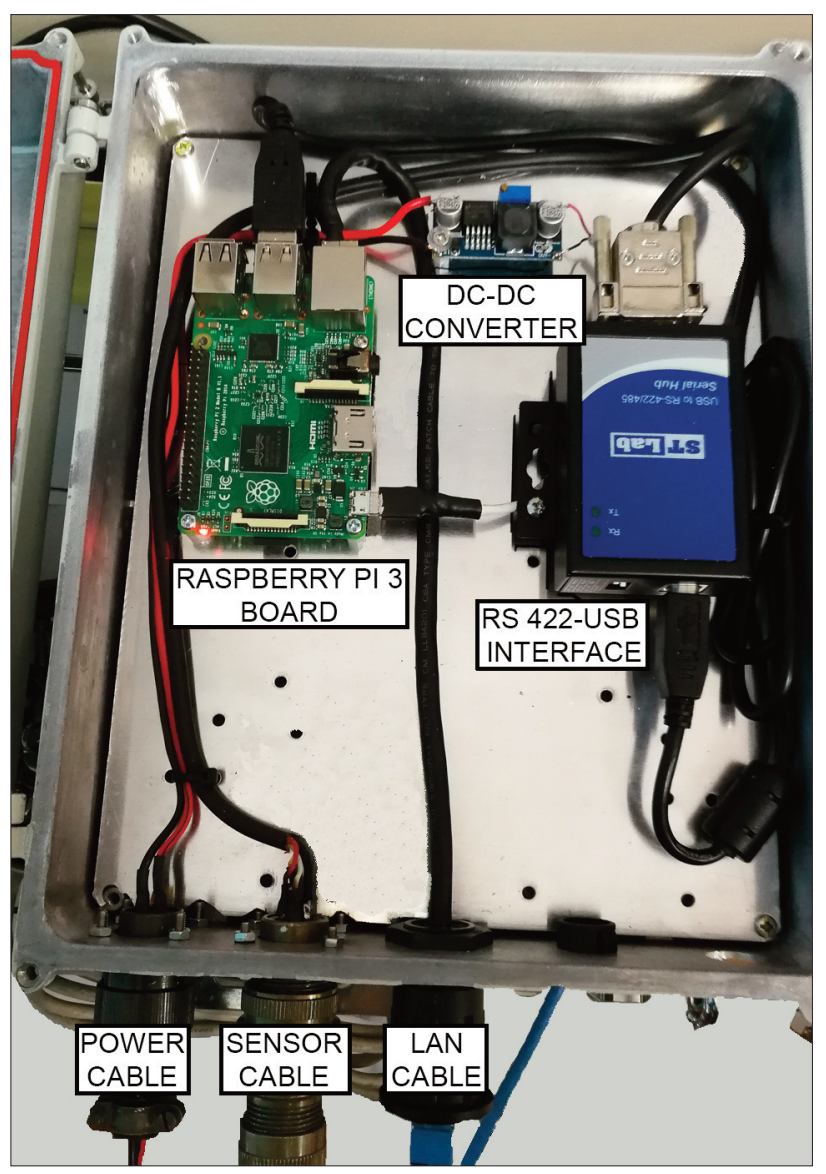

Figure 9. Datalogger developed by INGV-OV. 


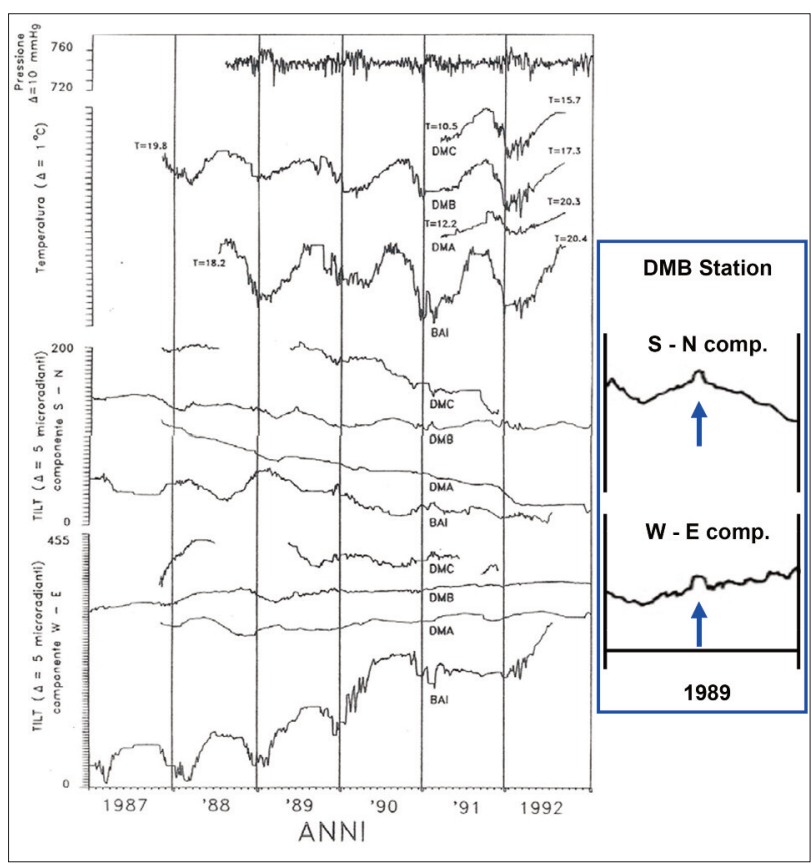

Figure 10. Ground tilt, temperature and atmospheric pressure recorded at Campi Flegrei network from 1987 to 1992 by horizontal pendulums made by P.A. Blum (I.P.G.P.) In the first half of 1989 DMB station recorded a tilt change on both components, highlighted with the arrows in the blue box.

In order to reduce the problems associated with data transmission from remote stations, it is impor- tant to set-up a datalogger to be linked to the tilt stations. For these purposes a proprietary system has been developed at Osservatorio Vesuviano (INGVOV). This new datalogger, based on a Raspberry PI 3 board and an RS422-USB interface, provides both signal acquisition and storage (Figure 9).

The new features developed are: synchronizing the sensor acquisition time, time reference via NTP query on a trusted server, data acquisition and storage in daily files, control of some critical value with corresponding alarms.

\section{Observations and conclusion}

In the study of ground deformation through the use of optical inclinometers, the first significant results were obtained in the late 1980s and early 1990s. During this period the acquisition of the tilt signals allowed the definition of the deformation pattern caused by descending bradyseism, at Phlegrean Fields, and to highlight the tilt change occurred in the first half of 1989 (Figure 10). This change was associated with an uplift of $74 \mathrm{~mm}$ in Pozzuoli, subsequently measured by optical leveling. This episode interrupted the downward trend acting since 1985, after the Phlegrean Fields bradyseismic crisis of 1982-1984 [Ricco et al. 1991].

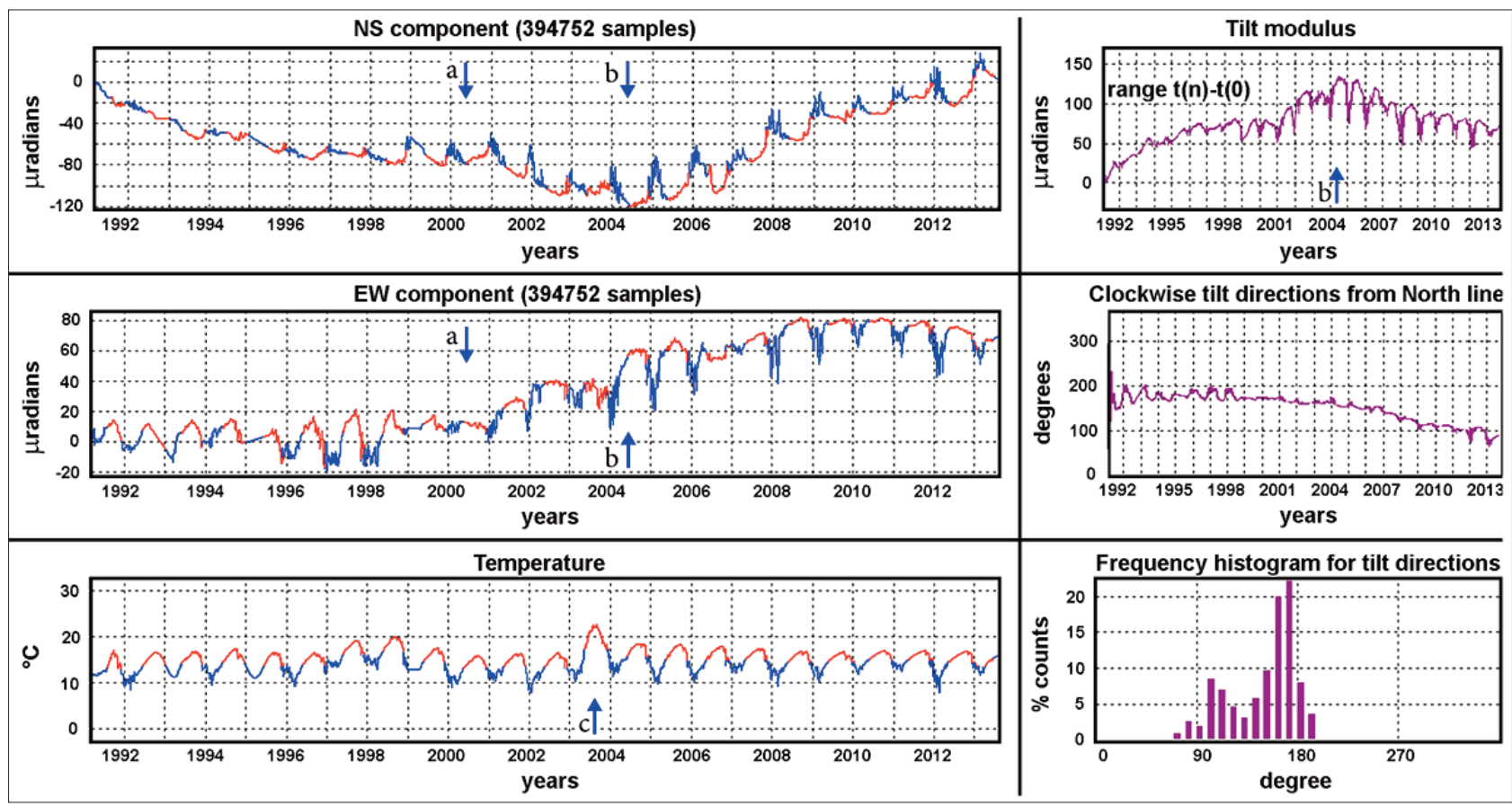

Figure 11. The figure shows the trend of both the NS and EW components of the tilt vector and the temperature recorded from 1991 to 2013 (left windows) by DMB, tilt station located about two km away from the maximum deformation area of Phlegrean Fields, along the NNW direction. Red and blue colors show the periods of soil heating and cooling. At the right-hand side of the picture, we report other parameters derived from tilt components, respectively: tilt magnitude, azimuth and its relative frequency histogram. The tilt increase on the NS component must be interpreted as northward inclination of the ground while the tilt increase on the EW component as an eastward inclination. The SE tilting occurs irregularly and shows the seasonality consistent with the solar thermal radiation, from 1991 until March 2000, when occurs a brief uplift lasted six months (arrow a). Then the ground started to subside until the last months of the 2004 when the subsidence ceased (arrow b). It must also be noted that the tilt magnitude reaches a maximum in 2004, when the subsidence come to an end (arrow b). Furthermore, in the temperature signal it can be noted the anomalous heating (arrow c), caused by heat wave that hit Europe during summer 2003. 


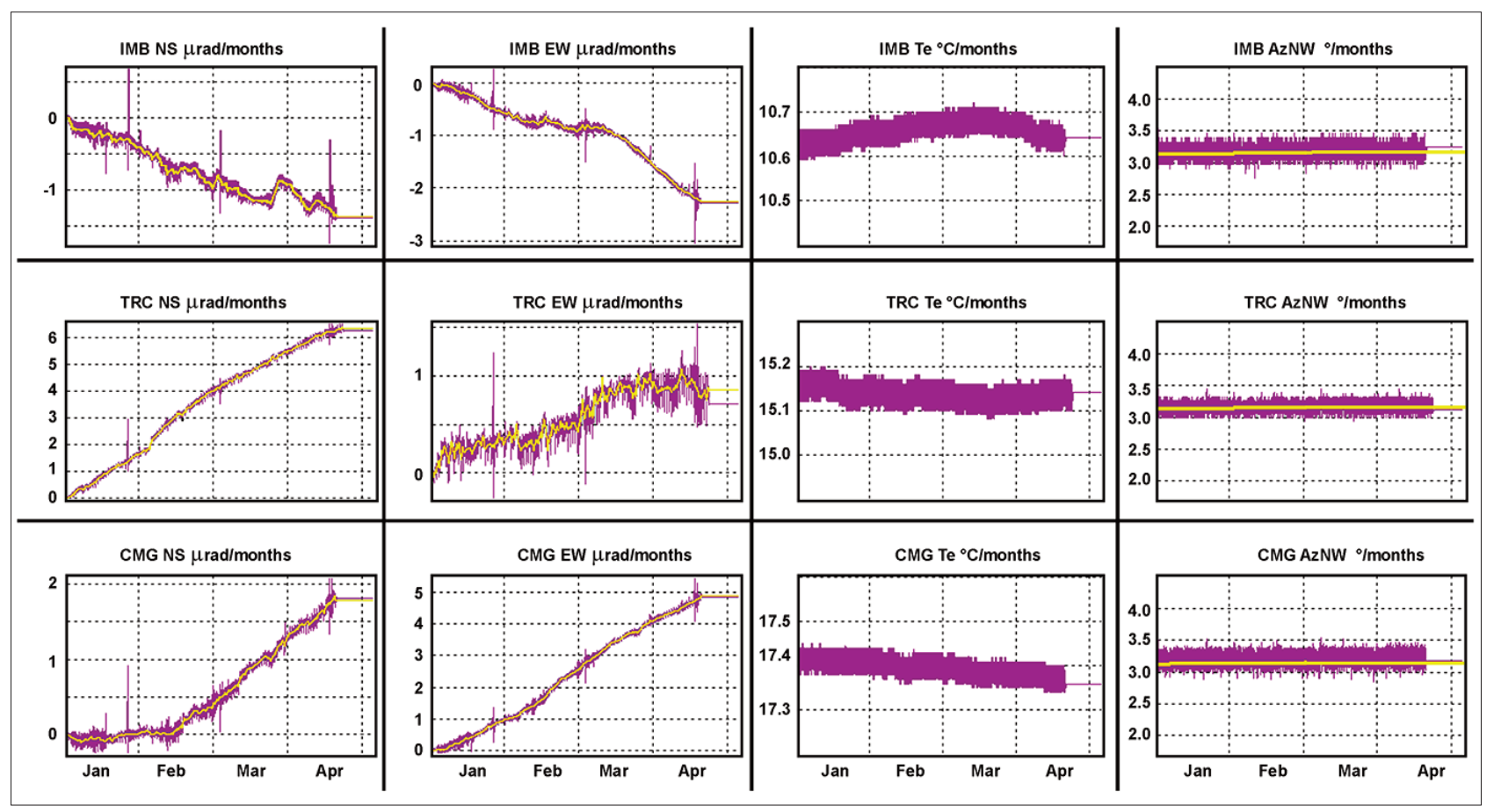

Figure 12. Digital signals recorded by the Vesuvius tilt-borehole network in the first three months of 2016. Tilt components, with daily filtered signals superimposed in yellow, are plotted in violet at the left-hand side of the picture. The figure also shows are the temperatures recorded at the well bottom and the magnetic azimuth. The yellow lines overlapped on the magnetic signals correspond to the theoretical values calculated using the International Geomagnetic Reference Field (IGRF-12) model.

Between 1991 and 1992, technological upgrades allowed configuring a new network of electronic sensors. One of the most significant findings of the tilt monitoring was the recording of a hiatus in the ground subsidence at Phlegrean Fields, interrupted in the year 2000 (Figure 11) by a modest trend change occurred between March and August of the same year [Achilli et al. 2001].
Moreover, the understanding of the tilt signals acquired by electronic sensors allowed detecting the end of the subsidence phase in the last months of the 2004 [Del Gaudio et al. 2005, Del Gaudio et al. 2010].

The digital switch-over, as well as the borehole installations to prevent temperature perturbations on the recorded signals, has heralded significant improvements

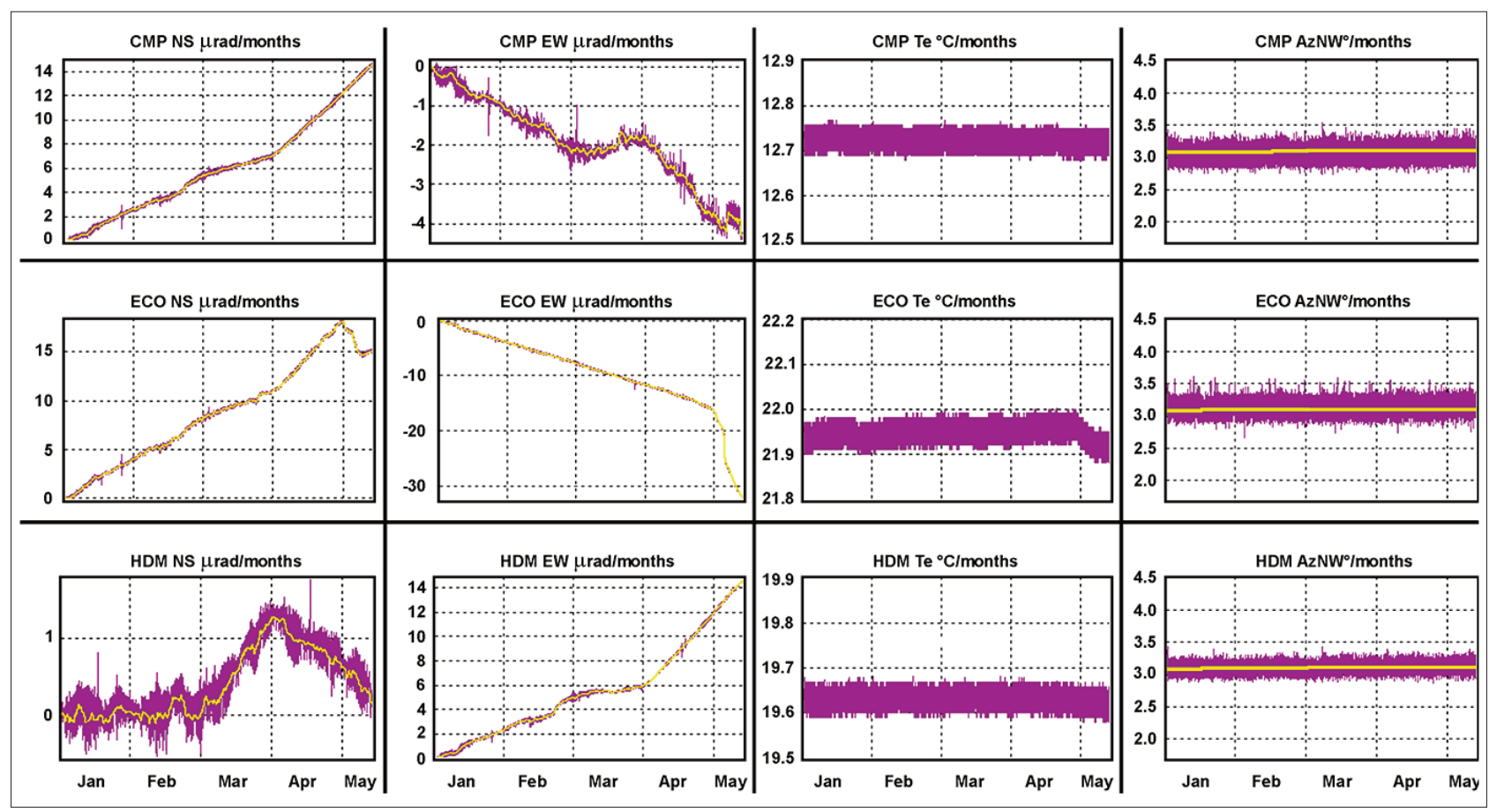

Figure 13. Digital recorded signals by the Campi Flegrei tiltmetric borehole network in the first 4.5 months of 2016 (for further explanations see Figure 12). 


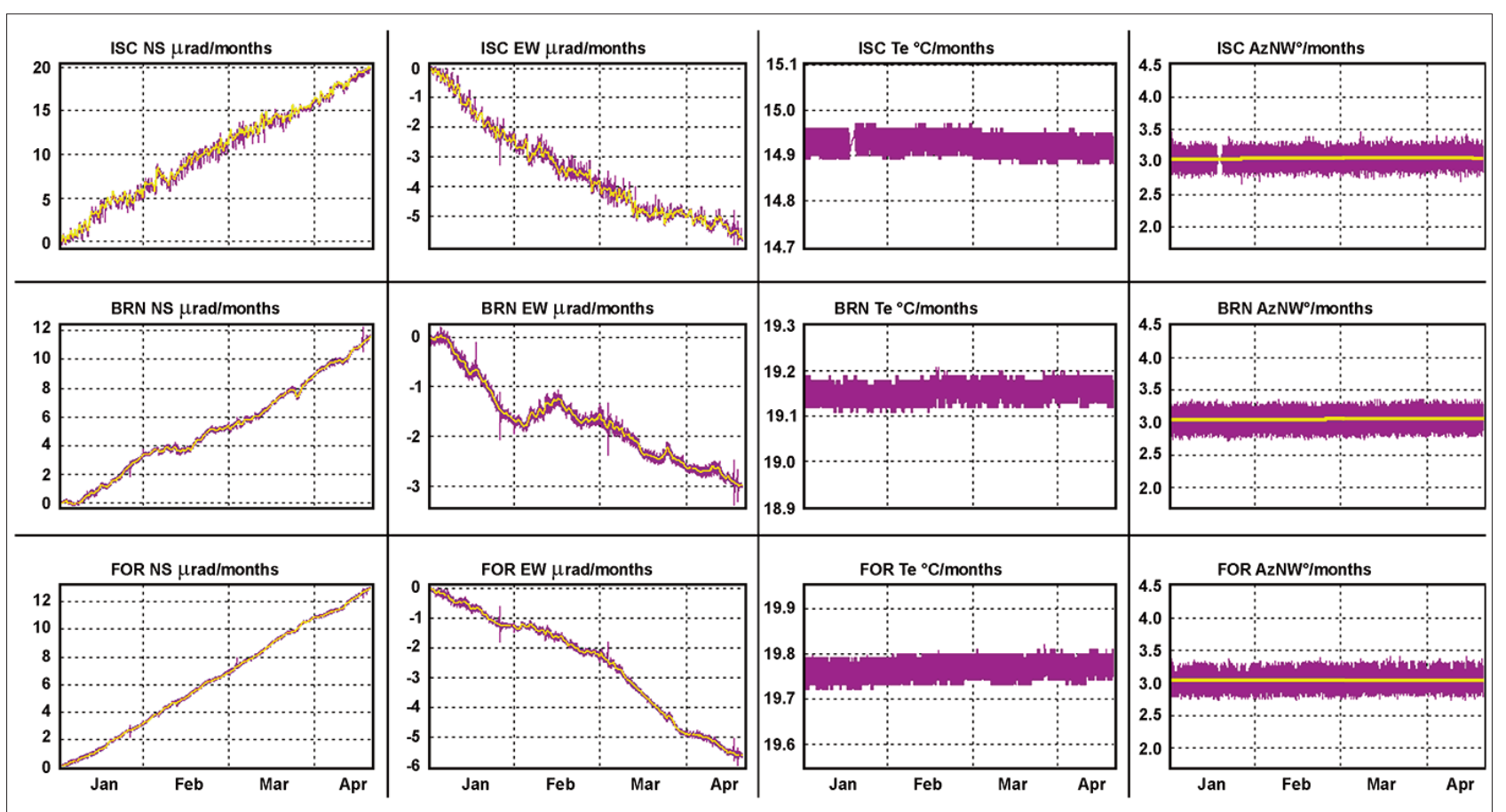

Figure 14. Digital signals recorded by the Ischia tiltmetric borehole network in the first 3.5 months of 2016 (for further explanations see Figure 12).

in the monitoring of ground tilt variations. This will help us collecting more and better information on the volcano dynamics of monitored areas.

The new data enhance, in the case of Phlegrean Fields (Figure 12) and Vesuvius (Figure 13) [Ricco et al. 2013], the old ones recorded by tilt surface network and they open new frontiers in the study of the deformation field of the Ischia Island as well, where ground tilting is being monitored for the first time (Figure 14).

It is important to point out that the signals recorded by Lily tiltmeters do not need to be filtered of the S1 diurnal principal solar and S2 semi-diurnal principal solar components which, conversely are always present in the surface time-series. The data recorded by these sensors can be used after the standard pre-processing to correct spikes and/or electrical transients and filtering solid earth tides. Their accuracy, together with the control of the sensor rotation in the well through the magnetic parameter, allows a straightforward recording of the true tilt signals.

Currently 10 digital sensors are recording tilt changes at Vesuvius, Phlegrean Fields and Ischia Island. Some of them are co-located with some of the old 10 analog stations. This large amount of data allows detecting tilt changes in the three Neapolitan volcanic areas. During the last 30 years, using data acquired in the different sites, we obtained useful results for the study of ground deformation and the assessment of the volcanic dynamics for the Neapolitan volcanoes.

Currently the tiltmetric network allows studying the ongoing unrest phase at Phlegrean Fields which started at least since 2004 [D'Auria et al. 2011] as well as the complex movements of the crustal layers of the Vesuvius, driven by the gravitational spreading of the volcanic edifice and a similar phenomena on Ischia Island, where the tilting shows a predominant N-NW direction.

\section{References}

Achilli, V., O. Al-Bayari, I. Aquino, P. Berardino, S. E. Borgstrom, G. Cecere, C. Del Gaudio, P. De Martino, M. Fabris, D. Galluzzo, R. Lanari, W. Marzocchi, A. Menin, G. P. Ricciardi, C. Ricco, G. Salemi, E. Sansosti, V. Sepe, V. Siniscalchi, M. Tesauro, (2001). Un approccio multimetodologico per il monitoraggio geodetico dell'area flegrea, Atti del I Convegno AUTEC, Napoli 17-18 Maggio 2001, 159-168.

AGI, (1995). Tiltmeter temperature coefficients: source, definition and use to improve accuracy, Technical Report no. B-95-1005, Rev. C.

AGI, (1997). 700-Series platform and surface mount tiltmeters, User’s Manual, User's Manual no. B-881016, Rev. E.

AGI, (2001). Model 798-A Handi-Logger User's Manual TelephoneTelemetry Option, User's Manual, no. B-01-1008, Rev. E.

AGI, (2005). LILY Self-Leveling Borehole Tiltmeter, User's Manual, no. B-05-1003, Rev. D.

Aquino, I., C. Ricco, C. Del Gaudio, (2006). Rete tilt- 
metrica dell'area napoletana, Open File Report INGV, N. 4.

Aquino, I., C. Ricco, C. Del Gaudio, V. Augusti, G. Scarpato, (2016). Potenziamento delle reti tiltmetriche dell'area vulcanica campana: rapporto sull'attività svolta nell'ambito del Progetto VULCAMED. Rapporti Tecnici INGV, 348, 51 pp, ISSN 2039-7941. Aste, J. P., P. A. Blum, J. L. Bordes, B. Memier, B. Saleh, (1986). Utilisation d'un clinometre à trés haute resolution pour l'etude du comportement des ouvrages de génie civil, Revue Française de Géotechnique, N.34, 57-67.

Briole, P., (1987). Les Reseaux d'Inclinometrie de l'Etna et de Pozzuoli, IPG Paris.

D’Auria, L., F. Giudicepietro, I. Aquino, G. Borriello, C. Del Gaudio, D. Lo Bascio, M. Martini, G. P. Ricciardi, P. Ricciolino, C. Ricco, (2011). Repeated fluid-transfer episodes as a mechanism for the recent dynamics of Phlegrean Fields caldera (1989-2010), J. Geoph. Res. VOL. 116, B04313, doi:10.1029/2010JB007837

Del Gaudio, C., C. Ricco, I. Aquino, G. Brandi, C. Serio, V. Siniscalchi, (2005). Misure di livellazione di precisione e dati tiltmetrici per il controllo delle deformazioni del suolo ai Campi, Open File Report INGV N. 4.

Del Gaudio, C., I. Aquino, G. P. Ricciardi, C. Ricco, R. Scandone, (2010). Unrest episodes at Phlegrean Fields: A reconstruction of vertical ground movements during 1905-2009, Journal of Volcanology and Geothermal Research, 195(1), 48-56, doi:10.1016/j.jvolgeores.2010.05.014.

Dzurisin, D. (2006). Volcano deformation: new geodetic monitoring techniques, Springer Science $\&$ Business Media.

Harrison, J. C., (1976). Cavity and topographic effects in tilt and strain measurements, Journal of Geophysical Research, 81, 319-328.

Harrison, J. C. and K. Herbst, (1977). Thermoelastic strains and tilts revised, Geophysical Research Letters, 4, 535-537.

Jewell Instruments, (2013). LILY Self-Leveling Borehole Tiltmeter, User's Manual, no. B-05-1003, Rev. G.

Luongo, G., C. Del Gaudio, F. Obrizzo and C. Ricco, (1998). La rete tiltmetrica OV-IPG operante ai Phlegrean Fields, Atti del $74^{\circ}$ Congresso Nazionale della Società Geologica Italiana, A.

Ricco, C., C. Del Gaudio, F. Obrizzo and G. Luongo, (1991). Misurazioni delle variazioni delle inclinazioni del suolo ai Phlegrean Fields, Atti X Convegno GNGTS, Roma, Italy, II, 1003-1012.

Ricco, C., I. Aquino and C. Del Gaudio, (2003). Ground tilt monitoring at Phlegraean Fields (Italy): a methodological approach, Annals of Geophysics, 46 (6), 1297-1314.

Ricco, C., I. Aquino, S. E. Borgstrom and C. Del Gaudio, (2007). A study of tilt change recorded from July to October 2006 at the Phlegrean Fields (Naples, Italy), Annals of Geophysics, 50(5), 661-674.

Ricco, C., I. Aquino, S. E. Borgstrom, Del C. Gaudio, (2013). 19 years of tilt data on Mt. Vesuvius: State of the art and future perspectives, Annals of Geophysics, 56, 4, 2013, S0453; doi:10.4401/ag-6459.

Tikhonov, A. N., and A. A. Samarskii, (2013). Equations of mathematical physics, Courier Corporation. ISO 690.

Zadro, M. and C. Braitenberg, (1999). Measurements and interpretations of tilt-strain gauges in seismically active areas, Earth Science Reviews, 47, 151-187.

\footnotetext{
*Corresponding author: Ida Aquino, Istituto Nazionale di Geofisica e Vulcanologia, Sezione di Napoli Osservatorio Vesuviano, Napoli, Italy; email: ida.aquino@ingv.it.
}

(C) 2018 by the Istituto Nazionale di Geofisica e Vulcanologia. All rights reserved. 